\title{
THE AFFECTIVE SYMPTOMS OF EARLY ONSET OF A FIRST- EPISODE PSYCHOSIS
}

\author{
Calderón, M. ${ }^{*}$ Royo, A. ${ }^{*}$, Gayete, S. ${ }^{*}$, Usall, J. ${ }^{*}$, Vila-Badía, R. . , Del Cacho, N. ${ }^{*}$ y Butjosa, A. ${ }^{*}$, Dolz, M. ${ }^{* *}$ y \\ Ochoa, S.*.
}

*Parc Sanitari Sant Joan de Déu. Sant Boi de Llobregat. Barcelona. España.

**Hospital Sant Joan de Déu de Barcelona. Esplugues de Llobregat. Barcelona. España.

\section{Background and aims}

There is a high prevalence of depressive symptoms in adults with a first episode psychosis(FEP) (Addington D, Addington J, \& Patten S., 1998). In children and adolescents there is not enough research, moreover there is lack of knowledge about the relationship between specific depressive symptoms and psychotic symptoms.

The aim of study is to study the prevalence of depressive symptoms, as well as, the type of depressive symptoms, in people with early onset FEP.

\section{Method}

Cross-sectional study of 62 people with FEP. Inclusion criteria: 2 or more psychotic symptoms, age between 7 and 17 years, 6 months or less from initial contact with medical services. The instruments used were sociodemographic and clinic questionnaire, the Positive and Negative Syndrome Scale (PANSS) and The Children Depression Inventory (CDI). The cut point for depression is 19 (Kovacs, 1981).

\section{Results}

A total of $23(37.1 \%)$ patients of the sample scored over the cut point for depression. Regarding the type of affective symptoms, the most prevalent were: "It's always hard for me to do my homework" (41.9\%), "I'm doing badly in subjects that I did well in before" (32.3\%), "Things always cause me worry"(30.6\%), "I 'm always worried about pain and illness" (25.8\%) and "I never have fun at school" (22.6 $\%$.

Table: Prevalence of presence of depressive symptoms (those with $10 \%$ or higher percentage of prevalence)

\begin{tabular}{|l|l|}
\hline \multicolumn{1}{|c|}{ CDI item present (max. score) } & Cumulative percentage > 10\% \\
\hline Item 9. I feel like crying every day. & $12.9 \%$ \\
\hline Item 10. Things always cause me worry. & $30.6 \%$ \\
\hline Item 11. I don't want to be with people at all. & $11.3 \%$ \\
\hline Item 13. I'm ugly. & $17.7 \%$ \\
\hline Item 14. It's always hard for me to do my homework. & $\mathbf{4 1 . 9 \%}$ \\
\hline Item 15. I have trouble getting to sleep every night. & $17.7 \%$ \\
\hline Item 16. I'm always tired. & $17.7 \%$ \\
\hline Item 17. Most days I don't feel like eating. & $12.9 \%$ \\
\hline Item 18. I'm always worried about pain and illness. & $25.8 \%$ \\
\hline Item 19. I always feel alone. & $12.9 \%$ \\
\hline Item 20. I never have fun at school. & $22.6 \%$ \\
\hline Item 21. I don't have friends. & $11.3 \%$ \\
\hline Item 22. I'm doing badly in subjects that I did well in before. & $32.3 \%$ \\
\hline Item 23. I'll never be as good as the other children. & $14.5 \%$ \\
\hline Item 26. I get into fights often. & $14.5 \%$ \\
\hline
\end{tabular}

\section{Conclusions}

High percentage of people with an early onset of a FEP scored for depression. The most prevalent depressive symptoms are associated with scholar area. This results suggest that the affective symptoms of early FEP are different than those found in adults. 